\title{
Field emission from multiwall carbon nanotubes prepared by electrodeposition without the use of a dispersant
}

\author{
S. M. Lyth, ${ }^{\text {a) }}$ F. Oyeleye, and R. J. Curry \\ Nanoelectronics Centre, Advanced Technology Institute, School of Electronic and Physical Sciences, \\ University of Surrey, Guildford, Surrey GU2 7XH, United Kingdom \\ J. Davis \\ School of Biomedical and Natural Sciences, \\ Nottingham Trent University, Clifton Lane, Nottingham NG11 8NS, United Kingdom \\ S. R. P. Silva \\ Nanoelectronics Centre, Advanced Technology Institute, School of Electronic and Physical Sciences, \\ University of Surrey, Guildford, Surrey GU2 7XH, United Kingdom
}

(Received 14 October 2005; accepted 29 March 2006; published 10 May 2006)

\begin{abstract}
We present a technique of manufacturing multiwall carbon nanotube (MWNT) field emitters by a nickel electrodeposition process, without using a surfactant to disperse the MWNTs in solution. Sonication adequately disperses individual MWNTs throughout the solution and MWNTs can be deposited onto a copper substrate. However, over time there is a reduction of the free MWNT concentration in solution and an associated change in the morphology of the deposit. The initial concentration of MWNTs in solution also plays a crucial role in the morphology of the deposits. The threshold field of electron field emission measurements remained in the order of $20 \mathrm{~V} / \mu \mathrm{m}$ regardless of the deposition conditions. (c) 2006 American Vacuum Society.
\end{abstract}

[DOI: $10.1116 / 1.2198855]$

\section{INTRODUCTION}

Carbon nanotubes ${ }^{1}$ (CNTs) are potential candidates to be used as electron field emission sources due to their high electrical conductivity, their ability to support large current densities, their mechanical strength, chemical stability, thermal conductivity, and their high aspect ratio. Field emission from CNTs has potential for use in flat screen displays with high brightness and good contrast ratios ${ }^{2}$ and as high efficiency light sources. ${ }^{3}$ Chemical vapor deposition is commonly used to manufacture CNT field emission cathodes, but this is generally carried out at temperatures in excess of $600{ }^{\circ} \mathrm{C}$ at high voltages and often requires the vacuum deposition of a catalyst layer. A low-temperature, low voltage, vacuum-free alternative that is suited to large-scale production could make field emission displays real contenders in the display industry. CNT deposition via an electrodeposition process could provide a viable method of deposition over large areas as part of an industrialized process. It has been $\operatorname{shown}^{4-6}$ that CNTs can be codeposited with nickel onto various substrates, using a suitable surfactant to disperse the CNTs in solution.

In the present study, multiwall carbon nanotubes were deposited with nickel onto copper substrates by electrodeposition, without the use of a dispersant. The electron field emission properties of the resulting electrodeposits were studied.

\section{EXPERIMENT}

Unpurified multiwall carbon nanotubes (MWNTs) grown by chemical vapor deposition were added to a nickel-plating bath $(0.013$ and $0.005 \mathrm{mg} / \mathrm{ml})$ comprising typically of $1 M$

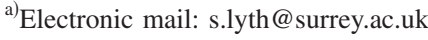

$\mathrm{NiSO}_{4} \cdot 6 \mathrm{H}_{2} \mathrm{O}, 0.2 M \mathrm{NiCl}_{2}$, and $0.5 M \mathrm{H}_{3} \mathrm{BO}_{3}$. Due to their hydrophobic nature, MWNTs do not disperse naturally in aqueous solutions, so the nickel-plating bath was sonicated (frequency of $50-60 \mathrm{~Hz}$, power of $0.09 \mathrm{kV} \mathrm{A}$ ) for $15 \mathrm{~min}$ prior to electrodeposition which was found to sufficiently disperse the MWNTs. All reagents were obtained from Aldrich, which were of the highest grade available and were used without further purification. Solutions were prepared daily using de-ionized water from an Elgostat (Elga, UK) ultrahigh quality (UHQ) grade water system with a resistivity of not less than $18 \mathrm{M} \Omega \mathrm{cm}$.

Electrochemical measurements were conducted using a $\mu$ Autolab computer controlled potentiostat with a threeelectrode configuration. Copper plates with an exposed surface area of $2 \mathrm{~cm}^{2}$ were used as cathodes. A spiral wound platinum wire served as the counter electrode, with a spiral wound $\mathrm{Ag}: \mathrm{AgCl}$ wire the reference electrode. Deposition was performed at $-1 \mathrm{~V}$ potential throughout. The typical cell volume was $10 \mathrm{~cm}^{3}$, maintained at a temperature of $20 \pm 2{ }^{\circ} \mathrm{C}$. After deposition, samples were thoroughly rinsed in de-ionized water to remove nickel salts and then dried in a nitrogen gas flow.

The resulting electrodeposits were imaged using a Phillips XL30 scanning electron microscope (Fig. 1). Finally, the samples were subjected to field emission characterization using a $5 \mathrm{~mm}$ spherical stainless steel anode. Although a spherical anode is used, it is assumed that the electric field between the anode and the surface of the sample can be modeled as a parallel plate. The emission current was recorded as a function of macroscopic electric field at a vacuum of around $10^{-6} \mathrm{mbar}$. Current readings were taken as an average of 100 measurements obtained once the voltage 

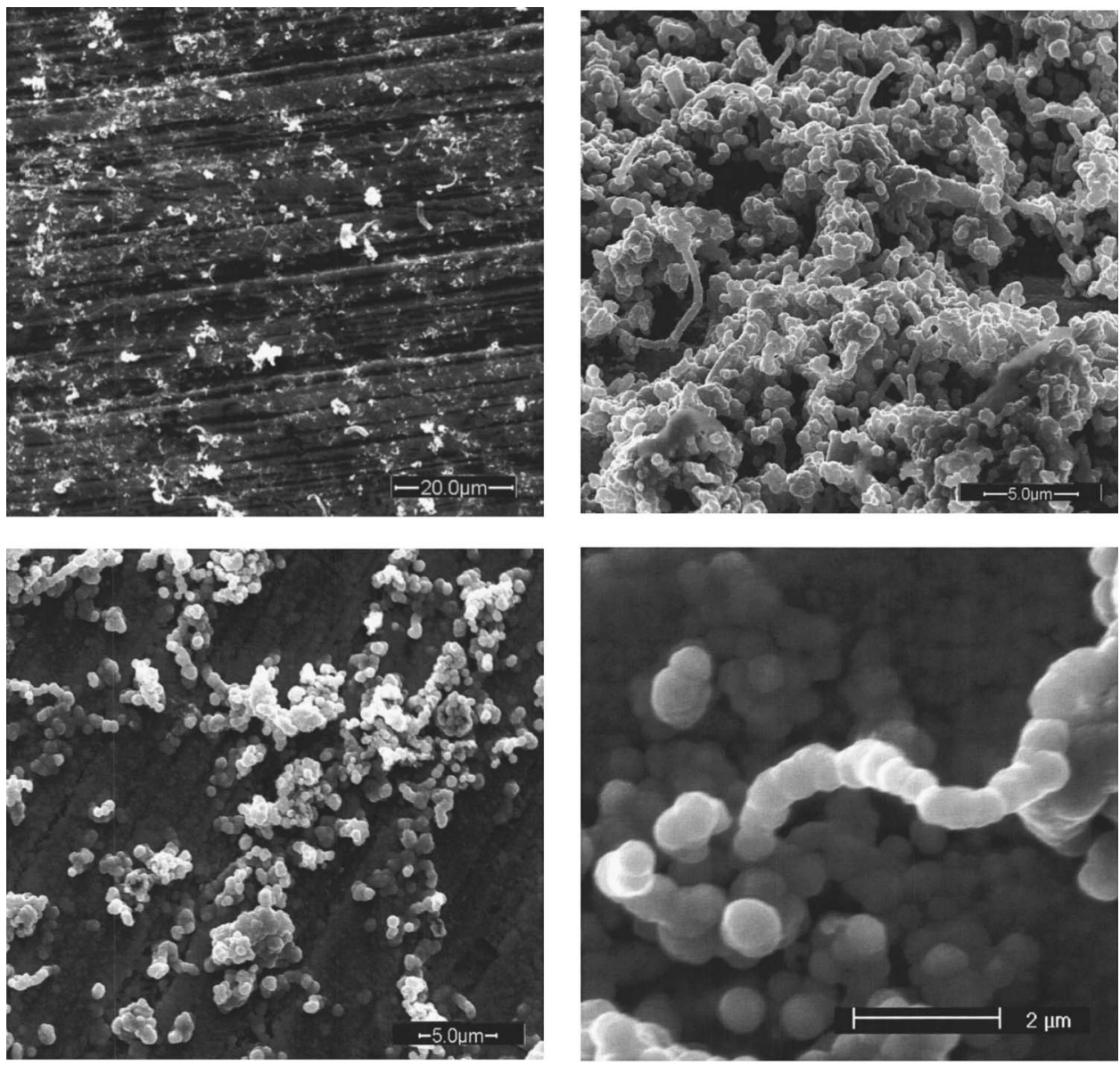

FIG. 1. Scanning electron microscope images of substrates formed by electrodeposition of nickel salts and MWNTs in solution: (a) $0.013 \mathrm{mg} / \mathrm{ml}$ MWNT immediately after sonication, (b) $0.013 \mathrm{mg} / \mathrm{ml}$ MWNT $5 \mathrm{~min}$ after sonication, (c) $0.005 \mathrm{mg} / \mathrm{ml}$ immediately after sonication, and (d) magnified portion of (c).

had stabilized. The anode voltage was generally incremented in $30 \mathrm{~V}$ steps from 0 to $2200 \mathrm{~V}$ with a current limit set at $10 \mu \mathrm{A}$. The threshold field was taken to be the field at which an emission current of $1 \mathrm{nA}$ was detected. The macroscopic electric field was calculated by dividing the applied voltage by the electrode gap, which was typically $25 \mu \mathrm{m}$.

\section{RESULTS AND DISCUSSION}

Figure 1 shows typical scanning electron microscope images obtained of the MWNT electrodeposits. Importantly, these deposits were observed after the samples were thoroughly rinsed in de-ionized water, suggesting that there is a strong adhesion between the MWNT and the substrate surface. In Fig. 1(a), a $0.013 \mathrm{mg} / \mathrm{ml}$ MWNT solution was deposited immediately after sonication. Little or no nickel is observed on the sample, but MWNTs of various sizes are adhered to the substrate uniformly over large areas $\left(>0.15 \mathrm{~mm}^{2}\right)$. Figure $1(\mathrm{~b})$ shows the same solution deposited 5 min after sonication. It can clearly be seen that much more nickel is present, although the uniformity is very poor. Nickel beads approximately $1 \mu \mathrm{m}$ in diameter encase individual MWNTs. The difference in morphology between the two samples could be due to rebundling of the MWNTs in solution once sonication has ceased, reducing the effective free MWNT concentration in solution with time.

Figures 1(c) and 1(d) show a $0.005 \mathrm{mg} / \mathrm{ml}$ MWNT solution deposited under the same conditions as in Fig. 1(a). A

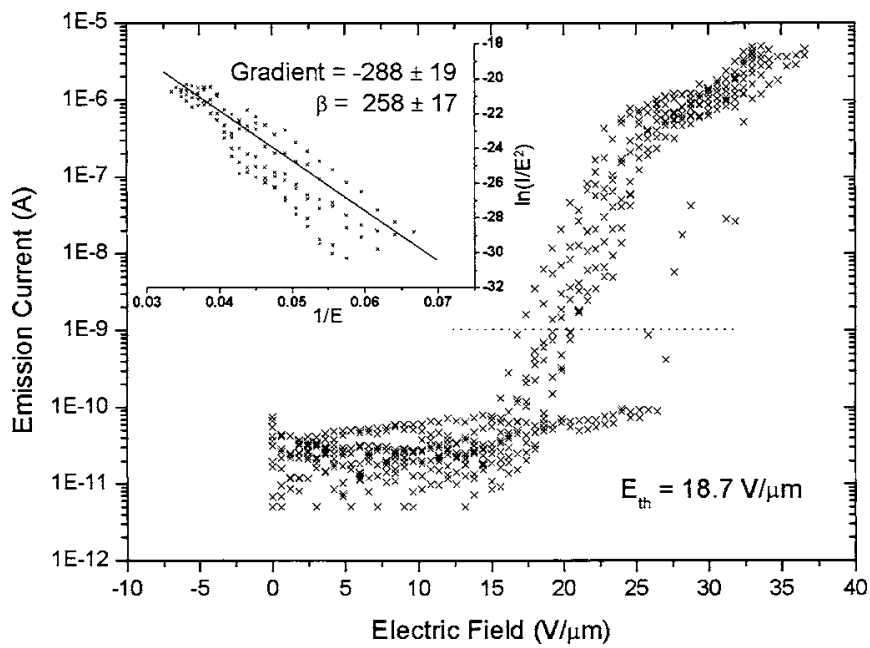

FIG. 2. Typical field emission current vs applied electric field for electrodeposited MWNT and nickel on copper substrates. (Inset) Fowler-Nordheim plot. 
thicker nickel coating is observed, which is uniform over areas greater than $30 \mu \mathrm{m}$. This is as expected, since for the same amount of nickel deposited per unit time, fewer MWNTs are available to be deposited. Therefore it can be seen that the relative concentrations of nickel salts and MWNTs are crucial in determining the morphology of the resulting deposits.

All of the samples displayed promising field emission characteristics, with threshold fields of the order of $20 \mathrm{~V} / \mu \mathrm{m}$ (Fig. 2). To exclude the possibility of electron field emission from the copper substrate or deposited nickel without MWNT, the emission properties prior to nickel deposition as well as after nickel deposition without any MWNT were tested. The results of these measurements revealed only background noise below $40 \mathrm{~V} / \mu \mathrm{m}$, confirming that the emission is due to the deposited MWNT and nickel film. The Fowler-Nordheim equation ${ }^{7}$ was used to infer the field enhancement factor $(\beta)$ of one of the samples (Fig. 2). ${ }^{8}$ Assuming that the field emission comes mainly from the nickel coating (work function of $4.9 \mathrm{eV}$ ), $\beta$ was calculated to be about 258 , i.e., the local field at emission sites was 258 times the macroscopic applied electric field. It is expected that altering the morphology of the deposits (e.g., by changing the deposition time, the voltage, and concentrations of MWNTs and nickel salts) could lead to improved threshold fields from the samples.

\section{SUMMARY}

Electrodeposition was used to deposit MWNT and nickel over large areas on copper substrates. A surfactant was not used to disperse the MWNTs in solution, as sonication provided ample free MWNTs for deposition. Resulting films had a beaded morphology and were strongly adhered to the copper substrate surface. It was found that the concentration of MWNTs in solution is crucial in determining the morphology of the deposits. Electron field emission revealed threshold fields in the order of $20 \mathrm{~V} / \mu \mathrm{m}$ for all of the samples.

\section{ACKNOWLEDGMENT}

The authors would like to thank EPSRC for funding this research.

${ }^{1}$ S. Iijima and T. Ichihashi, Nature (London) 354, 56 (1991).

${ }^{2}$ J. Chen, S. Z. Deng, and N. Xu, Ultramicroscopy 89, 105 (2001).

${ }^{3}$ J. Bonard, T. Stockli, O. Noury, and A. Chatelain, Appl. Phys. Lett. 78, 2775 (2001).

${ }^{4}$ K. Yamamoto, S. Akita, and Y. Nakayama, J. Phys. D 31, L34 (1998).

${ }^{5}$ S. Arai and M. Endo, Electrochem. Commun. 5, 797 (2003).

${ }^{6}$ H. Kang, S. Lee, and H. Lee, J. Vac. Sci. Technol. B 23, 2 (2005).

${ }^{7}$ R. Fowler and L. Nordheim, Proc. R. Soc. London 119, 173 (1928).

${ }^{8}$ Q. Wang, T. Corrigan, J. Dai, and R. Chang, Appl. Phys. Lett. 70, 3308 (1997). 